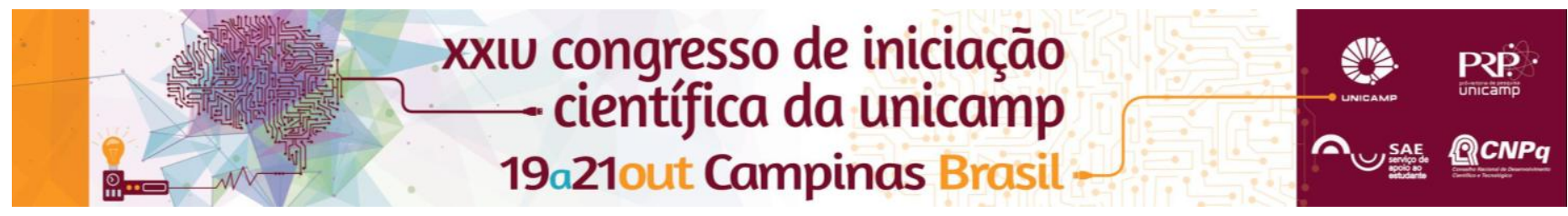

\title{
Práticas de Geologia Estrutural e visualização 3D com uso do programa Ester para projeção estereográfica
}

\section{Giovanni Amaral Guimarães*, Celso Dal Ré Carneiro}

\begin{abstract}
Resumo
O projeto envolve revisão bibliográfica sobre Geologia Estrutural, ensino de Geociências, fundamentos e aplicações da projeção estereográfica em Geologia. A pesquisa tem como meta avaliar a eficácia do software Ester, testar a exatidão dos produtos com dados reais e contribuir para atualizá-lo, dentro de um projeto mais abrangente acerca de técnicas de aprendizado e visualização 3D. Pretende-se publicar um software sintético e inovador, redigido em Português e Inglês. O método de trabalho concentra-se em testes práticos comparativos. São elaborados sucessivos diagramas a partir da base de dados disponível, sendo feita posterior comparação com diagramas resultantes de outros sistemas. Ao longo da pesquisa verificou-se que o software Ester é sintético, completo e possui interface bem amigável.
\end{abstract}

\section{Palavras-chave: Projeção Estereográfica, Geologia Estrutural, Análise Estatística.}

\section{Introdução}

A projeção estereográfica envolve a representação de feições espaciais em um plano, correspondente à seção equatorial de uma esfera de referência. Existem diversos softwares específicos que permitem produzir com rapidez diagramas estereográficos em microcomputadores.

O uso das redes estereográficas facilita o entendimento de situações geológicas complexas, pois elas permitem estudar e interpretar desde feições microscópicas, até feições continentais como grandes lineamentos, direções de encurtamento e sistemas regionais de dobramento.

O projeto focalizou o teste do programa Ester, que foi desenvolvido como sistema de código aberto. O método de trabalho envolve testes comparativos, sempre com a mesma base de dados, usando softwares tradicionais: Stereonet, Stereonet9, Dips, QuickPlot e OpenStereo. O objetivo central é oferecer subsídios para atualizar a versão atual do programa e concluir a produção de um pacote de ferramentas computacionais, depois de testálas e investigar aplicações nos campos técnico-científico (Pollard 2000, Fowler \& Hashem 2014), profissional (Kincal 2014) e educacional (Blenkinsop 1999).

\section{Resultados e Discussão}

Depois da inserção de uma gama de dados em diversos softwares de Projeção Estereográfica, nota-se que a plotagem assim como o resultado do gerenciamento estatístico dos dados em ambiente Ester são idênticos aos gerados nos aplicativos já consagrados disponíveis. Para as versões futuras do Ester espera-se inserir uma opção de adicionar um Grid ao diagrama, que melhorará a noção espacial dentro do ambiente. Pretende-se adicionar uma opção para fixar o número central dentro do gráfico em roseta, um intervalo de $0^{\circ} \pm 5^{\circ}$ ao invés de um intervalo $0^{\circ}$ até $10^{\circ}$ e outro de $0^{\circ}$ até $-10^{\circ}$ e por fim, com menor necessidade, melhorar a resolução das manchas de densidade de dados. Ester mostra-se superior em conceitos muito práticos, que acabam facilitando sua utilização nos trabalhos. O software está disponível em Português e Inglês; outro fator que pesa a favor do Ester é de que a inserção de dados pode ser realizada no ambiente do aplicativo, não sendo necessário gerar um arquivo .txt, sendo essa maneira de abordagem ainda possível, existindo duas formas, utilizando uma barra de ferramentas rápida, para poucos dados, e uma forma mais extensa, quando existe uma gama de dados maior. Algumas ferramentas disponíveis se destacam em Ester: é possível gerar conversões de medidas e também uma função de cálculo de interseção. A ferramenta de rotação de dados e ângulos entre estruturas também está disponível em outros aplicativos.

Figura 1. Ambiente Ester $2.1 \mathrm{com}$ as funções disponíveis

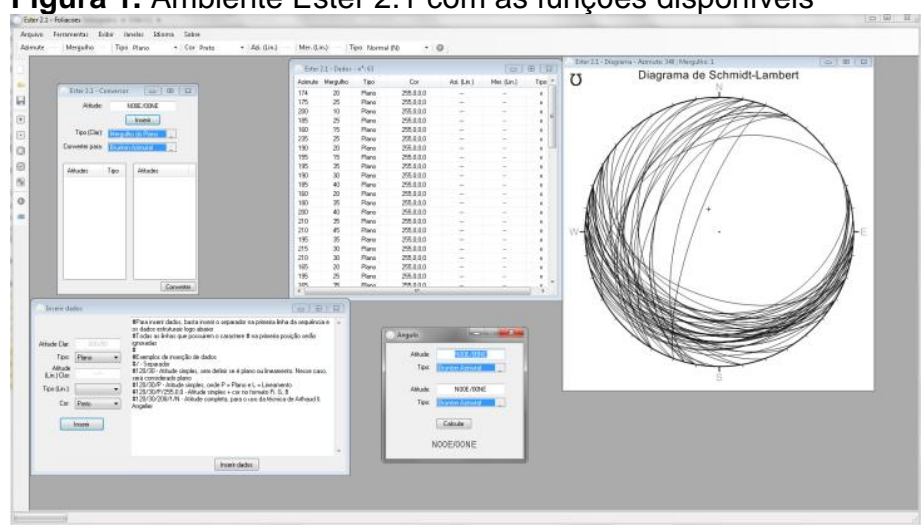

Tabela 1. Dados de foliações, em notação Clar, coletados durante atividade de campo em Carrancas-MG.

\begin{tabular}{l|l|l|l|l|l|l|l|l}
\hline $174 / 20$ & $175 / 25$ & $200 / 20$ & $200 / 20$ & $185 / 25$ & $160 / 15$ & $235 / 25$ & $190 / 20$ & $155 / 15$ \\
\hline $195 / 35$ & $195 / 30$ & $190 / 30$ & $185 / 40$ & $160 / 35$ & $180 / 35$ & $200 / 40$ & $200 / 40$ & $210 / 35$ \\
\hline $210 / 45$ & $195 / 35$ & $215 / 30$ & $210 / 30$ & $165 / 20$ & $195 / 25$ & $165 / 35$ & $185 / 20$ & $210 / 20$ \\
\hline $220 / 40$ & $200 / 50$ & $185 / 35$ & $180 / 15$ & $200 / 30$ & $190 / 20$ & $280 / 50$ & $285 / 50$ & $290 / 30$ \\
\hline $290 / 75$ & $300 / 50$ & $285 / 65$ & $280 / 40$ & $300 / 40$ & $275 / 35$ & $300 / 30$ & $300 / 30$ & $305 / 30$ \\
\hline
\end{tabular}

\section{Conclusões}

Ester mostrou-se completo, sendo mais sintético que os demais, por reunir um modo prático de entrada de dados, com a vantagem de ser redigido em Português e Inglês. $\mathrm{O}$ ambiente, amigável, oferece diversas ferramentas que facilitam pesquisas em Análise Estrutural.

\section{Referências}

Blenkinsop T. Pedagogy of stereographic projection. J. African Earth Sci. 1999, 28(4):897-902.

Fowler A.-R. \& Hashem W. A simple application of stereographic projection in the measurement of stratigraphic thickness. J. Struct. Geol, 2014, 54:180183.

Kincal C. A application of two new stereographic projection techniques to slope stability problems. Inter. J. Rock Mech. \& Mining Scien. 2014, 66:136150.

Pollard D.D. Strain and stress: Discussion. J. Struct. Geol. 2000, 22(2000):1359-1367 